\title{
Proposal of new vibro-acoustic floor
}

\author{
Andrzej Kłosak ${ }^{1}$, Alicja Kowalska-Koczwara ${ }^{* 1}$, Filip Pachla ${ }^{1}$, Krzysztof Stypuła ${ }^{1}$, Tadeusz \\ Tatara $^{1}$, Bogusław Zając ${ }^{1}$ \\ ${ }^{1}$ Cracow University of Technology, Warszawska 24 St., 31-155 Krakow, Poland
}

\begin{abstract}
Human perception of vibration could be the basic parameter in designing a new buildings located close to public transport. It is also one of parameter that is considered in diagnosis of building vibration. People perceived vibrations through the floor. The problem of floor vibration appear especially in old historical buildings with wooden floor when source of transport vibration change because of infrastructure development. During years road, tramway or railway infrastructure is more expanded that it was when the old buildings were built. That is why new solutions of protection against noise and vibration are needed. One of that kind solution could be vibro-acoustic floor which can reduce impact sounds and vibrations. A flooring system that insulates both acoustically and vibrantly is a common solution to reduce noise coming from impact sounds or to propagate from lower levels to higher ones and to limit the influence of vibration on people receiving vibration in buildings passively. The flooring system should therefore be capable to damp vibrations up to $100 \mathrm{~Hz}$ and have sound insulation of min. $25 \mathrm{~dB}$. The composition of vibration insulation materials and their material parameters will be selected to optimize the acoustic and vibration protection. At the same time, the acoustic and vibration-insulating flooring system should have all the functional features that are common to the floor: ease of installation and adequate rigidity. In paper three types of vibro-acoustic floors will be considered: with full vibro-insulation, with insulation strips and with point insulation. Advantages and disadvantages of these three considered solutions will be presented. The paper is pilot study to in-situ measurement which will be held under the project of EU commission support.
\end{abstract}

\section{Introduction}

Vibro-acoustic floors could be an alternative for vibro-insulation in source of vibration [1-2] and on the way of transmission [3]. Vibro-acoustic floors especially floating floor are known and are the subject of investigation in the past few years [4-6], but researches focus on impact sound insulation systems and they do not take into account a possibility to reduce vibrations in buildings that are transmitted through the soil. Vibro-acoustic floor proposed in this paper is intended to reduce not only impact sounds but also environmental vibrations. Basic layer in proposed vibro-insulating floor system will be vibro-insulation mat which will be introduced to the floor in three ways: as full layer, as insulation strips and as point insulation

\footnotetext{
* corresponding author, e-mail address: akowalska@pk.edu.pl
} 
system (fig. 1). The main goal is to ensure reduction for impact sounds of min. $25 \mathrm{~dB}$ and to ensure increase of about $40 \%$ in vibration insulation in relation to pure structure.

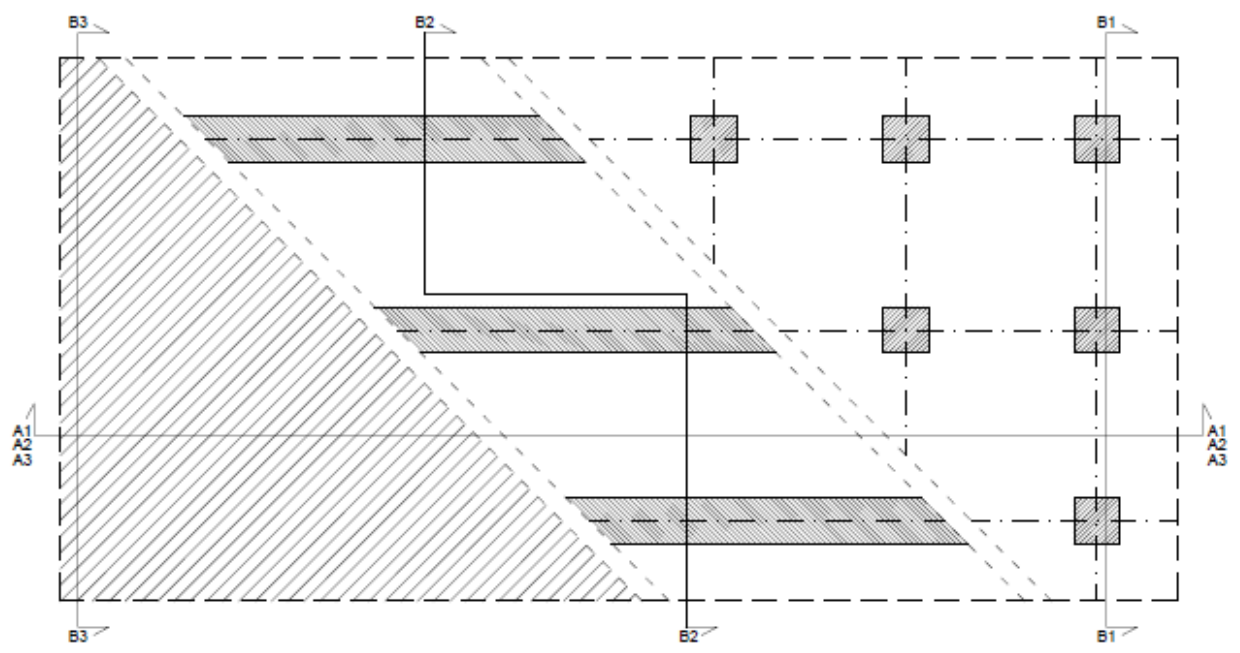

Fig. 1. Schematic diagram of three types of floor with vibro-insulation mats.

Proposed vibro-acoustic floor should be of course relatively cheap for competitive solutions. That is why three different types of floor will be considered.

First stage to develop new vibro-acoustic floor is to determine material characteristic of vibro-insulation mats which will play the main role in reduction impact sounds and environmental vibrations. Some characteristic of that type of material are known better or worse, for example Poisson ratio [ex. 7], Young modulus [ex. 8], density [ex.9]. Problem is when dynamic properties of that kind of materials are considered. That is why for better understanding and for better FEM modelling, dynamical properties of vibro-insulating materials such as dynamic stiffness and damping ratio will be measured in the first stage of vibro-acoustic floors investigation. In this paper pilot studies of damping ratio measurements are described.

\section{Damping ratio measurements}

Pilot studies were conducted for four different polymers [10 and Table 1].

Table 1. Material properties of polymers.

\begin{tabular}{|c|c|c|c|} 
material & $\begin{array}{c}\text { density } \\
{\left[\mathrm{kg} / \mathrm{m}^{3}\right]}\end{array}$ & $\begin{array}{c}\text { Eps. } \\
\text { max }\end{array}$ & work temp. \\
\hline PS & $\sim 1400$ & $40 \%$ & -40 do +80 \\
\hline PM & $\sim 950$ & $110 \%$ & -40 do +80 \\
\hline PMM & $\sim 950$ & $110 \%$ & -40 do +80 \\
\hline PBM & $\sim 1030$ & $110 \%$ & -40 do +80 \\
\hline
\end{tabular}


Concrete beam was stabilized between two specimens of polymers (up and down, fig.2). The system was loaded with six intensity of loads $(0.05-0.2-0.4-0.6-0.8-1 \mathrm{MPa})$ and was oscillated by the modal hammer in horizontal direction (fig.2). Three piezoelectric accelerometers were placed to measure a response of that system. Two were placed on the beam (at the beginning and at the end of it) and reference accelerometer was placed on the machine.

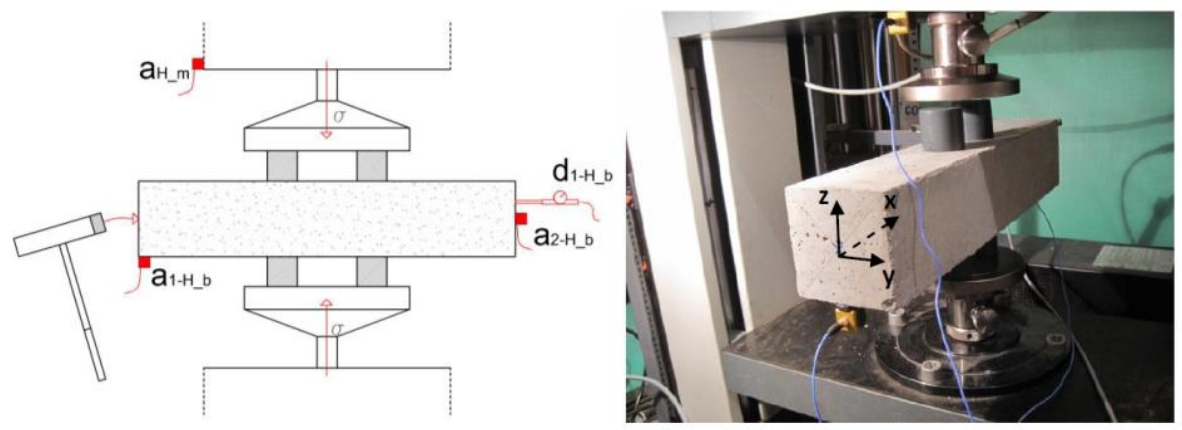

Fig. 2. Schematic diagram and real feature of experiment.

\subsection{Logarithmic decrement and critical damping evaluation}

Two main ratios are nowadays used to described damping: logarithmic decrement (1) and critical damping (2). Formula of logarithmic decrement was given in [11]

$$
\Delta=\frac{1}{n} \ln \left(\frac{A_{1}}{A_{n+1}}\right)
$$

where: $n$ - sum of cycles, $A_{1}$ and $A_{n+1}$ amplitudes of any two successive peaks.

$$
\xi=\frac{\Delta}{2 \pi}
$$

Logarithmic decrement could be determined from free vibration diagram (fig.3). Critical damping could be determined from formula (2) or from resonance curve if natural vibrations are separated from each other [12]. During this experiment both methods were used to determine damping ratio.

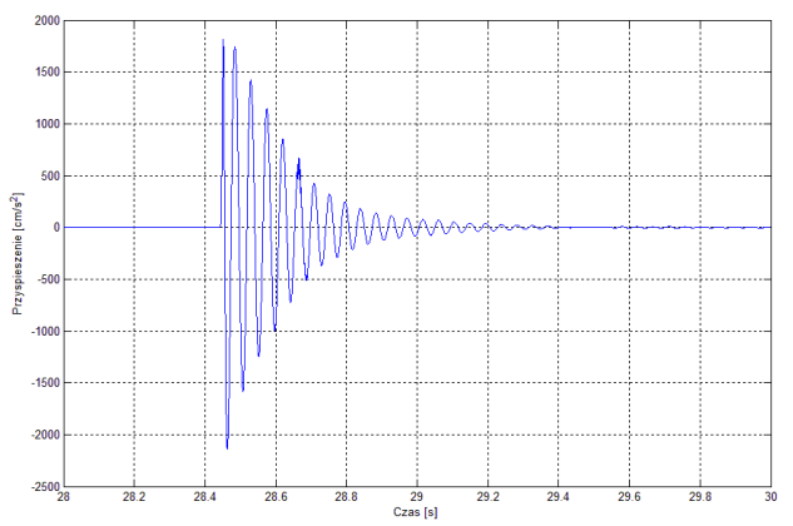

Fig. 3. Free vibration for PSM material. 


\subsection{Results}

Every four polymers were examined and results of damping ratios for horizontal direction for one of them (PBM) are listed in Table 2.

Table 2. Damping ratios results for PBM material.

\begin{tabular}{|c|c|c|}
\hline Load [MPa] & $\Delta[-]$ & $\xi[-]$ \\
\hline 0.05 & 0.26 & 0.042 \\
\hline 0.2 & 0.28 & 0.045 \\
\hline 0.4 & 0.35 & 0.061 \\
\hline 0.6 & 0.42 & 0.070 \\
\hline 0.8 & 0.47 & 0.082 \\
\hline 1.0 & 0.48 & 0.087 \\
\hline
\end{tabular}

Trends in critical damping ratio for all four polymers that were investigated during pilot studies are shown in Figure 4.

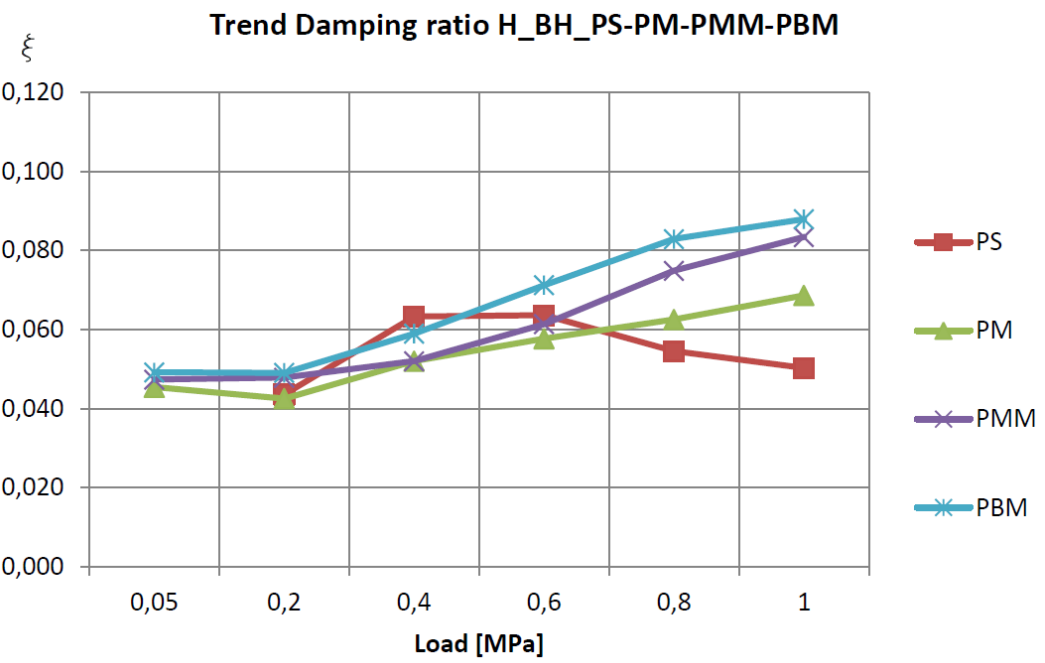

Fig. 4. Critical damping ratio values for different polymers.

\section{Conclusion}

Measurements results show that dynamic properties of polymer materials change with loading - the higher load, the higher value of damping ratio in horizontal direction. Only PS polymer which is hard material do not have that trend in damping characteristic.

Damping values obtained during measurements in comparison with values available from literature are reasonable. Measurements of floor construction and floor with all layers [13] show that value of logarithmic decrement equal 0.26-0.48 is proper for this kind of material. Similar conclusion could be find in [14] in which RC floor were laboratory tested in two stages of construction: with and without styrofoam and wood.

Exact damping characteristic is needed for FEM modeling and that is why additional measurement in both horizontal and vertical direction should be done on vibro-insulating mats that will be used for vibro-acoustic floor systems. Twelve materials (sometimes composites) will be investigated during laboratory tests. Materials will be loading by life load value for residential and office buildings. 
On the basis of results of FEM modeling most promising materials systems will be chosen for next step of vibro-acoustic floor investigation which are polygons and in-situ measurements. During polygons measurements will turn out which type of acoustic flooring system (full, striped or pointed) is effective enough to ensure assumed reduction for impact sounds and vibration insulation. Economical and functional aspects will be also strongly taken into account.

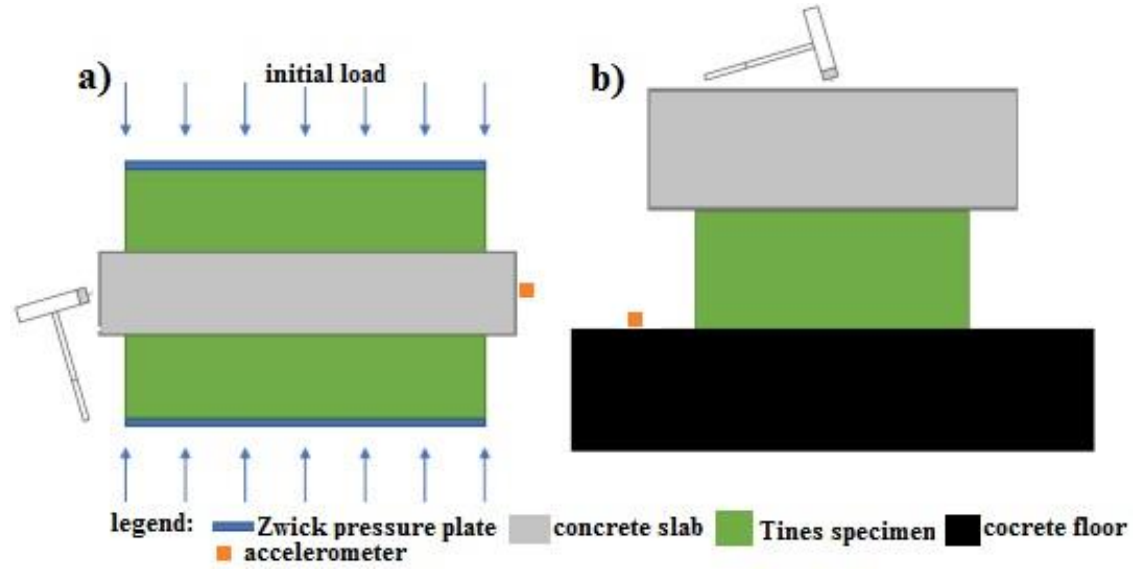

Fig. 5. Damping ratio measurements proposal in two different directions: a) horizontal, b) vertical.

Scientific research results were financed by the European Union from the European Regional Development Fund within the Smart Growth Operational Programme 2014-2020. "The innovative technology of vibro-acoustic floor insulation" project is implemented as a part of the Regional Science and Research Agendas (RANB) competition of the National Centre for Research and Development (NCRD)

\section{References}

[1] M. D. Stroia, ANUL XVI, 1 (2009)

[2] P. Alves Costa, R. Calcada, A. Silva Cardoso, Soil Dynamics and Earthquake Engineering 42 (2012)

[3] D. Makovic `ka \& D. Makovic `ka, Int. J. Comp. Meth. and Exp. Meas. 2 (2014)

[4] T. Cho, Journal of Sound and Vibration 332 (2013)

[5] J.-Y. Lee, J.-M. Kim, J. Kim, J. Kim, Journal of Sound and Vibration 366 (2016)

[6] H. S. Park, B. K. Oh, Y. Kim, T. Cho, Building and Environment 94 (2015)

[7] Y. Li, Ch. Zeng., Adv. Mat. 28 (2016)

[8] X. Cheng, K. W. Putz, Ch. D. Wood, C. Brinson, Macromol. Rapid Commun. 36 (2015)

[9] N. Saba, M.T. Paridah, M. Jawaid, Construction and Building Materials 76 (2015)

[10] M. Gubert, Ph.D. Thesis (2015) - in Italian

[11] R. Ciesielski, K. Kuźniar, E. Maciąg, T. Tatara, Archives of Civil Engineering 41 (1995)

[12] A. Kowalska. Scientific Papers of Silesian University of Technology, 102 (2004)

[13] H. Bachmann et al. , Bulletin D'Information, 209 (1991)

[14] J. Szulej, Ph. D. Thesis (2010) - in Polish 